\title{
LA EFICACIA EXTERNA O (ALCANCE) HORIZONTAL DE LOS DERECHOS FUNDAMENTALES. LA APLICACIÓN (VINCULACIÓN) DE LOS DERECHOS FUNDAMENTALES EN LAS RELACIONES PRIVADAS (LABORALES). UN ANÁLISIS (CRÍTICO) A LA LUZ DE LA REALIDAD BRASILEÑA Y ARGENTINA
}

Fábio Nadal Pedro*

SUMARIO: 1-) Introducción. 2-) La (nueva) visión de la eficacia o (alcance) vertical de los derechos fundamentales y la desconstrucción del principio de la supremacía del interés público. 3-) De la eficacia externa u (alcance) horizontal de los derechos fundamentales. 3.1-) Teoría de la eficacia inmediata o directa de vinculación (alcance) de los derechos fundamentales. 3.2-) Teoría de la eficacia mediata o indirecta de vinculación (alcance) de los derechos fundamentales. 3.3-) Teoría del State Action Doctrine (Public Function Theory). 4-) Crítica a la eficacia externa $\mathrm{u}$ (alcance) horizontal de los derechos fundamentales. 5-) La adopción por Brasil y Argentina de la Teoría de la eficacia inmediata o directa de vinculación (alcance) de los derechos fundamentales. 6-) Conclusión. 7-) Bibliografía.

\section{1-) Introducción.}

El tema involucra al análisis de la eficacia de los derechos fundamentales en las relaciones entre particulares, a partir del desarrollo dogmático de los derechos humanos de posguerra, en especial, en Alemania, y la constatación del "fenómeno de la constitucionalización" que deflagró un gradual desaparecimiento de la frontera entre el derecho constitucional y el restante del ordenamiento jurídico, sobre todo el derecho privado.

Finalizada la Segunda Guerra Mundial, los Estados Occidentales, hundidos en un paradigma democrático de legitimidad do poder $^{63}$, pasaron a editar normas protectoras de los derechos humanos (rectius, protección a la dignidad de la persona humana) ${ }^{64}$, con el propósito

\footnotetext{
*Mestre em Direito Constitucional pela Pontifícia Universidade Católica de São Paulo. Professor de Direito Constitucional e Direito Tributário. Procurador da Câmara Municipal de Jundiaí.

${ }^{63}$ Sobre el paradigma democrático de Estado, ver nuestro: NADAL, Fábio. A constituição como mito. O mito como discurso legitimados da Constituição. São Paulo: Método, 2006, páginas 62-66. Para Ives Gandra Martins, la democracia, como técnica de libertad, impone mayor complejidad para la conquista y ejercicio del poder. In MARTINS, Ives Gandra. Una breve teoría del poder. São Paulo: Revista de los Tribunales, 2009, página 195.

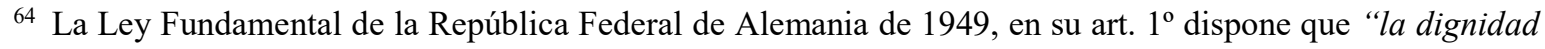
de la persona humana es intocable; respetarla y protegerla es obligación de todo el Poder Público”.
} 
de tornar remota la reedición de modelos ideológicos semejantes al nazismo alemán o fascismo italiano (modelos despóticos y absolutistas) ${ }^{65}$.

En el plano internacional ${ }^{66}$, la Organización de las Naciones Unidas albergó la Declaración Universal de los Derechos Humanos (1948) que en su preámbulo (rectius, espíritu de la declaración) apunta que: "el reconocimiento de la dignidad inherente a todos los miembros de la familia humana y de sus derechos iguales e inalienables es el fundamento de la libertad, de la justicia y de la paz en el mundo."

En razón de su "fuerza expansiva" (teoría de los derechos humanos), gana cuerpo la discusión de la aplicación de los derechos fundamentales en el ámbito de las relaciones privadas; locus registrado por el instituto de autonomía de las voluntades, en especial, en Alemania, durante los años 50 y 60 (drittwirkung o horizontalwirkung), así como también en los Estados Unidos de América (state action doctrine o public function theory).

No obstante, la conformación teorética/dogmática sobre el alcance (vertical y horizontal) de los derechos humanos no es gravada de univocidad, existiendo gran divergencia sobre su extensión y sus fines.

\section{2-) La (nueva) visión de la eficacia o (alcance) vertical de los derechos fundamentales y la desconstrucción del principio de la supremacía del interés público.}

\footnotetext{
65 Esta discusión, postsegunda guerra mundial, acerca de supremacía de los derechos humanos y rechazo al cumplimento de órdenes delictivas de tiranos inhumanos, puede ser bien evaluada en la obra de Gustav Radbruch, in RADBRUCH, Gustav, Arbitrariedad legal y derecho supralegal. Traducción: María Isabel Azareto de Vásquez. Argentina: Abeledo-Perrot, 1962. Observan German J. Bidart Campos y Walter F. Carnota que en razón de la referida "fuerza expansiva" de la teoría de los derechos fundamentales "hasta los estados socialistas y marxistas han incorporado al texto de sus constituciones una declaración de derechos, sólo que con una finalidad totalmente distinta y con una formulación también henchida de la ideología y del vocabulario que le son propios." (BIDART CAMPOS, German J. \& CARNOTA, Walter F. Derecho constitucional Comparado. Buenos Aires: Ediar. Tomo II, 2000, página 14).
}

66 Sobre la recepción del Derecho Internacional de los Derechos Humanos en el Derecho Constitucional Argentino, ver: MANILI, Pablo Luis. El bloque de constitucionalidad. La recepción del Derecho Internacional de los Derechos Humanos en el Derecho Constitucional Argentino. Buenos Aires: La Ley. 2003. En el ámbito del Derecho Internacional prevalece, de la misma forma, la supremacía de las Convenciones y Tratados de Derechos Humanos, como Derecho Supranacional, y que no pueden, en relación a los Estados signatarios del pacto, ser distanciados, a posteriori, en razón de obstáculos constitucionales (Derecho Interno de un país), conforme enseña Augustín Gordillo (GORDILLO, Augustín \& FLAX, Gregorio (Orgs.). Derechos Humanos. Buenos Aires: Fundación de Derecho Administrativo. $6^{a}$ edición, 2007, página III-1). Sobre el aparato internacional de protección de los derechos humanos y su efectivización, en especial, en el sistema jurídico brasileño, la obra de Flávia Piovesan (PIOVESAN, Flávia. Direitos humanos e Direito Constitucional Internacional. São Paulo: Saraiva. 12a edición, 2011). 
La "tensión dialéctica" que gravita sobre el tema no se circunscribe tan solo sobre la eficacia (alcance) horizontal de los derechos fundamentales, sino también en las relaciones entre Estado y ciudadano (eficacia vertical), alejando la visión apriorística de preponderancia sobre los intereses públicos en detrimento de los intereses privados, en todas las hipótesis de conflictos y colisiones, de forma monolítica y absoluta.

Basados sobre la teoría de los derechos fundamentales, autores replican la existencia del principio de la supremacía del interés público ${ }^{67}$ o le dan otra conformación, más ajustada a la axiología del Estado de Derecho Democrático ${ }^{68}$.

Por lo tanto, esta visión doctrinaria aleja la prevalencia teórica del interés público sobre los intereses individuales y particulares, imponiendo aquel que concretiza la función estatal de proceder una interpretación del "sistema de ponderaciones" (orientado por el principio de la proporcionalidad), visando alcanzar el "mejor interés público", en los dichos de Gustavo Binenbojm ${ }^{69}$.

En Brasil, el Supremo Tribunal Federal, al analizar la Acción Directa de Inconstitucionalidad no 1753-2/DF, Relator Ministro Sepúlveda Pertence, en que se discutía la ampliación de plazo para la propuesta de acciones rescisorias, por el Poder Público, de dos para

\footnotetext{
67 ÁVILA, Humberto Bergmann, "Repensando o princípio da supremacia do interesse público sobre o particular”. In: SARLET, Ingo Wolfgang (Org.). O Direito Público em tempos de crise. Porto Alegre: Livraria do Advogado, 1999, páginas 99-127; NEGREIROS, Teresa, "Dicotomia Público/Privado frente ao problema da colisão de princípios”. In: TORRES, Ricardo Lobo (Org.). Teoria dos direitos fundamentais. Rio de Janeiro: Renovar, 1999, páginas 337-375.
}

${ }^{68}$ DROMI, José Roberto. Sistema y valores administrativos. Buenos Aires: Ciudad Argentina, 2003, páginas 15-46. Para el referido autor hay garantías públicas (los derechos fundamentales) que deben ser preservadas frente a las prerrogativas públicas, propias del Estado. De la misma manera, aunque reconozca la distinción entre el régimen de derecho público y régimen de derecho privado, "esta distinción no implica confrontación, pues se intenta 'distinguir para unir',; FREITAS, Juarez de. O controle dos atos administrativos e os princípios fundamentais. $3^{\mathrm{a}}$. edición, São Paulo: Malheiros, 2004, páginas 34-36. Para el mencionado autor, el principio de la supremacía del interés público (por él denominado 'principio de interés público') “exige la simultanea subordinación de las acciones administrativas a la dignidad de la persona humana y el fiel respeto a los derechos fundamentales".

69 BINENBOJM, Gustavo. "Da supremacia do interesse público ao dever de proporcionaldiade: Um novo paradigma para o Direito Administrativo". In: SARMENTO, Daniel (Org.). Interesses públicos versus interesses privados: Desconstruindo o princípio da supremacia do interesse público. Rio de Janeiro: Lumen Juris, 2005, páginas 117-170. Por influencia del Estado de Derecho, se tornó "sentido común teórico" que el axioma de la supremacía del interés público (principio de la finalidad pública o principio del interés público), en la doctrina del Derecho Administrativo brasileño, no faculta a la Administración Pública tornar mezquino al derecho del particular. En ese sentido: NADAL, Fábio \& RIBEIRO, Vauledir. Direito Administrativo. Série Exame de Ordem. São Paulo: Método. $7^{\text {a }}$ edición, 2010, página 36. 
cinco años (privilegio procesal basado, en suma, en la falta de estructura de un Estado agigantado), basado sobre los principios de la proporcionalidad, razonabilidad, igualdad y de la supremacía del interés público, reconoció la inconstitucionalidad del dispositivo legal, en esencia, sobre un doble fundamento: (i) la suficiencia (razonabilidad) del plazo existente; (ii) el plazo ampliado debería beneficiar por igual a los particulares y no sólo al Poder Público

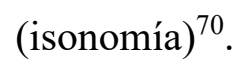

En Argentina, la Corte Suprema, en el caso "Pustelnik""71, de 1975, de forma oblicua, rompió con el axioma "apriorístico" de la supremacía del interés público, al distanciar la presunción de legitimidad de los administrativos nulos. La Suprema Corte entendió: “que dicha presunción de legitimidad de los actos administrativos no puede siquiera constituirse frente a supuestos de actos que adolecen de una invalidez evidente y manifiesta”.

\section{3-) De la eficacia externa o (alcance) horizontal de los derechos fundamentales.}

En un breve análisis de Derecho Comparado ${ }^{72}$, podemos identificar países que: (i) positivaron la eficacia (alcance) horizontal de los derechos fundamentales ${ }^{73}$; (ii) adoptaron la eficacia inmediata o directa horizontal de los derechos fundamentales ${ }^{74}$; (iii) adoptaron la

\footnotetext{
${ }^{70}$ En el mismo sentido, Supremo Tribunal Federal, Recurso Extraordinário n⿳0 148754 , Relator Ministro Carlos Velloso, In: RTJ 150/888-891. En este juzgamiento, el STF restringió el alcance del art. $6^{\circ}$, de la Medida Provisoria $n^{\circ} 314 / 93$, que suspendía todos los plazos procesales de la Unión, en el curso de la implantación de su Abogacía-General. El Supremo Tribunal Federal apartó la aplicación de la suspensión de los plazos procesales en los procesos en que la defensa de la Unión le cupiera a la "Fiscalía de la Hacienda Nacional", pues esta institución ya se encontraba bien estructurada, no existiendo motivos para tal beneficio.
}

${ }^{71}$ Corte Suprema de Justicia de la Nación, Fallos, 293:133. En el mismo sentido: el caso Acuña Hnos. y Cía., Fallos, 252:39-50, año 1962.

\footnotetext{
${ }^{72}$ El Derecho Comparado, conforme enseña José Cretella Júnior, no es disciplina jurídica autónoma, sino un método científico de observación y cotejo de los diversos sistemas jurídicos con intuito de verificar la universalidad de un concepto o por la tipificación de un instituto en un determinado sistema jurídico. Enseña el referido autor: "Le droit compare, comme on le sait bien, n'est pás une branche de l'arbre du droit. Ce n'est pás une discipline juridique autonome. Ce n'est pás du droit. C'est une méthode scientifique qui, em faisant appel à l'observation et à la confrontation, met em lumière les traits dominants de divers systèmes juridiques, em comparant sur le même plan, des instituts parallèles et des systèmes, pour conclure après pour l'universalité dún concept ou pour um seul type unique d'un institut dans um système donné de droit." (CRETELLA JÚNIOR, José. Droit Administratif Comparé. São Paulo: Editora de la Universidad de São Paulo. 1973, página 28).

73 Conforme dispuesto en el artículo 18, inciso I, de la Constitución de Portugal.

${ }^{74}$ Ejemplificadamente, adoptan tal teorización los siguientes países: Argentina, Brasil, España e Italia.
} 
eficacia mediata o indirecta de los derechos fundamentales ${ }^{75}$; y, (iv) adoptaron el posicionamiento según el cual los derechos fundamentales solamente vinculan al Estado (state action doctrine) o particulares que ejerzan funciones delegadas del Estado (public function theory ${ }^{76}$.

En Brasil y Argentina, que albergan la idea de la eficacia inmediata o directa horizontal de los derechos fundamentales, no existe norma positivada determinando la aplicación de los derechos fundamentales en las relaciones privadas. Tal entendimiento, de esta forma, decanta la idea (teoría) de la eficacia propagada de los derechos fundamentales, donde las normas de derecho privado, en especial, sus cláusulas generales y conceptos jurídicos indeterminados, no pueden generar antinomias con los parámetros contenidos en las normas fundamentales.

A partir del análisis de los sistemas jurídicos de varios países, insistimos, podemos divisar diversas teorizaciones sobre la aplicabilidad de los derechos fundamentales en las relaciones privadas ${ }^{77}$.

\section{1-) Teoría de la eficacia inmediata o directa de vinculación (alcance) de los derechos fundamentales.}

Por la influencia de Hans Carl Nipperdey, Juez del Tribunal Constitucional Alemán, se estructuró a inicios de la década del 50 (del siglo pasado), la teoría de aplicación de los derechos fundamentales directamente por el Poder Judiciario, sin ninguna intermediación del legislador (infraconstitucional), en el campo del Derecho Civil (rectius, esfera privada).

Para Hans Carl Nipperdey, los derechos fundamentales serían absolutos, pues (i) tendrían contenido invariable en el tiempo ( $\sin$ ninguna relación con la visión jusnaturalista o

\footnotetext{
75 Modelo adoptado, v.g., en Alemania.

76 Modelo adoptado, v.g., en los Estados Unidos de América.

77 Por fuerza del fenómeno de la internacionalización del Derecho, estas “categorizaciones", relativas al tema de eficacia/alcance horizontal de los derechos fundamentales, siguen, por procesos deductivos, casos paradigmáticos (v.g., caso Luth) tornando, tanto los sistemas de common Law como los de tipo romanista (statute law), operativamente abiertos, con franca incidencia de "conceptos jurídicos indeterminados". En ese sentido: MOHINO, Juan Carlos Bayón. "Internacionalización del derecho y metodología jurídica”. In DIAS, Jorge de Figueiredo (Org.). Internacionalização do Direito no novo século. Coimbra: Coimbra Editora, 2009, páginas 13-43.
} 
de inmutabilidad) y, (ii) no podría sufrir limitaciones, a pesar de lo restringible en la dinámica de aplicación en las relaciones entre particulares ${ }^{78}$.

Para esta teorización, la eficacia de los derechos fundamentales posee efecto absoluto, o sea, tiene eficacia directamente normativa, pudiendo modificar o crear normas de derecho privado $^{79}$. Se atribuye, indistintamente, a los derechos fundamentales, una doble dimensión (subjetiva y objetiva) que se irradia sobre todo el sistema jurídico, inclusive en el campo privado (rectius, el derecho civil).

Alertamos que existe variaciones surgidas en el seno de la doctrina constitucional sobre la extensión de la eficacia inmediata o directa de vinculación (alcance) de los derechos fundamentales. La primera vertiente apunta para su aplicabilidad incondicional de los derechos fundamentales en las relaciones privadas. La segunda vertiente limita la aplicación sólo para los casos derivados de desigualdades entre particulares. La tercera vertiente apunta para la aplicación directa, pero no de forma ilimitada o incondicional, existe la necesidad de intervención judicial y aplicación del principio de la ponderación (o proporcionalidad, en el sentido estricto $)^{80}$.

\section{2-) Teoría de la eficacia mediata o indirecta de vinculación (alcance) de los derechos fundamentales.}

La eficacia mediata de los derechos fundamentales tiene como precursor Gunther Dürig y como paradigma jurisprudencial la decisión proferida por el Tribunal Constitucional Federal Alemán, en el caso Luth-Urteil ${ }^{81}$ (caso involucrando la ordenación de valores y clarificación

\footnotetext{
${ }^{78}$ De acuerdo con Virgílio Afonso da Silva. (SILVA, Virgílio Afonso de. A constitucionalização do direito. Os direitos fundamentais nas relações entre particulares. São Paulo: Malheiros, 2005, página 88).

${ }^{79}$ Para H. C. Nipperdey: "El efecto jurídico es más bien un efecto directamente normativo que modifica las normas de derecho privado existentes, sin que importe que se trate de derecho vinculante o dispositivo, de cláusulas generales o de determinadas normas jurídicas, o cree otras nuevas, sean éstas prohibiciones, mandatos, derechos subjetivos, leyes de protección o razones de justificación.” (NIPPERDEY, Hans Carl, "Grundrecht und Privatrecht". In NIPPERDEY, Hans Carl (comp.). Festschrift für E. Molitor. Munich/Berlin, 1962, página 26; apud ALEXY, Robert. Teoría de los Derechos Fundamentales. Versión castellana: Ernesto Garzón Valdés. Madrid: Centro de Estudios Constitucionales, 1997, página 513).

${ }^{80}$ Conforme Ionilton Pereira do Vale. VALE, Ionilton Pereira. "A eficácia horizontal dos direitos fundamentais: a aplicação dos direitos fundamentais no âmbito privado". In Revista de Direito Privado. São Paulo: Editora Revista de los Tribunales, volumen 44 (octubre-diciembre 2010), páginas 58-76.

81 Tribunal Constitucional Alemán: BVERFGE 7, 198 (LUTH-URTEIL) - 15/01/1958:
}

“Reclamación constitucional contra decisión judicial. 
del relacionamiento entre derechos fundamentales - libertad de expresión - y derecho privado - reparación de daños a tercero, en razón de conducta atentatoria contra las buenas costumbres, en los términos del $\S 826$ del Código Civil alemán ${ }^{82}$ ).

Para esta teoría los derechos fundamentales, mientras sean "principios objetivos" 83 , influyen en la conformación/interpretación del derecho privado, más precisamente: (i) en la concretización/densificación semántica de las cláusulas generales de derecho privado (conceptos jurídicos indeterminados); (ii) en la interpretación de una norma de derecho privado; y, (iii) excepcionalmente, como justificación de decisiones tomadas contra el texto de una ley. No obstante, se mantiene la autonomía del derecho privado, limitándose la actuación del intérprete en el análisis de la influencia de los derechos fundamentales en las normas privadas.

Por lo tanto, la mediación de la aplicación de los derechos fundamentales, en el campo privado, primordialmente, compete al Poder Legislativo (dador legislativo) que debe disciplinar el derecho privado en los términos y parámetros constitucionales, en especial, resguardando los derechos fundamentales de los particulares, pero sin romper con los postulados propios del

1. Los derechos fundamentales son, en primera línea, derechos de resistencia del ciudadano contra el Estado. No obstante, a las normas de derecho fundamental se incorpora también un ordenamiento axiológico objetivo, que vale para todas las áreas del derecho como una fundamental decisión constitucional.

2. En el Derecho Civil, el contenido jurídico de los derechos fundamentales se desarrolla de modo mediato, por intermedio de las normas de derecho privado. Él interfiere, sobre todo, en las prescripciones de carácter convincente y es realizable por el juez, principalmente por la vía de las cláusulas generales.

3. El juez de salas civiles puede, por medio de sus decisiones, violar derechos fundamentales $(\$ 90$ $B V e r f G G)$, cuando ignore la influencia de los derechos fundamentales sobre el derecho civil. El Tribunal Constitucional Federal revisa decisiones civiles solamente en lo que respecta a tales violaciones de derechos fundamentales, pero no en relación a errores jurídicos en general.

4. Las normas de derecho civil también pueden ser "leyes generales" en la acepción del Art. 5 II GG $y$, de esta forma, limitar el derecho fundamental a la libertad de expresión del pensamiento.

5. El Derecho Fundamental del Art. 5 GG no protege solamente la expresión de una opinión mientras sea tal, sino también protege el efecto intelectual a ser alcanzado por su expresión...

6. Una expresión del pensamiento que contenga una convocación a boicot no viola necesariamente las buenas costumbres en la acepción de $\$ 826$ BGB; ella puede ser justificada constitucionalmente, en el marco de la ponderación de todos los factores involucrados en el caso, por medio de la libertad de expresión del pensamiento." (SCHWABE, Jürgen. Cinquenta anos de Jurisprudência do Tribunal Constitucional Federal Alemão. Traducción para la lengua portuguesa: Leonardo Martins (Org.), Beatriz Hennig, Mariana Bigelli de Carvalho, Tereza Maria de Castro y Vivianne Geraldes Ferreira. São Paulo: Konrad Adenauer Stiftung. 2005, página 382).

82 KOMMERS, Donald P. The Constitutional Jurisprudence of the Federal Republic of Germany. Durham and London: Duke University Press. 1997, página 361.

83 También denominados, según Robert Alexy, como "decisiones valorativas", "normas objetivas" o "valores jusfundamentales" y que influyen en la relación ciudadano/ciudadano (efecto horizontal). Conforme ALEXY, Robert. Teoría de los Derechos Fundamentales. Versión castellana: Ernesto Garzón Valdés. Madrid: Centro de Estudios Constitucionales, 1997, página 510. 
derecho privado (v.g., libertad en la conformación de su personalidad, forma libre de los pactos, autonomía de las voluntades, igualdad de las partes), con la finalidad de mantener la diferenciación (sub)sistémica entre los regímenes de derecho público y privado. Por su parte, al Poder Judiciario (dador jurisdiccional), en forma accesoria, a la luz de los derechos fundamentales de un determinado orden jurídico, le compete interpretar las cláusulas generales de derecho privado, dándoles mayor densidad semántica, bien como excepcionalmente, analizar la constitucionalidad de una norma de derecho privado (ley) que confronte con los derechos fundamentales.

\section{3-) Teoría del State Action Doctrine (Public Function Theory).}

La state action doctrine o public function theory, de matriz estadunidense, deriva de los límites de actuación gobernativa ${ }^{84}$ de la Suprema Corte, al definir los derechos fundamentales y sus respectivas protecciones, en el sentido de imponer las prácticas permitidas o exigidas por el Estado.

Para la Suprema Corte estadunidense esta actuación gobernativa en la definición y protección de los derechos fundamentales, más detenidamente, centradas en la aplicabilidad de la decimocuarta enmienda constitucional, solamente vincula el Estado (state action doctrine) o particulares que ejerzan funciones delegadas del Estado (public function theory) ${ }^{85} \mathrm{y}$, en ese último aspecto, de forma restrictiva.

Esta actual conformación del state action se levanta de la sustancial alteración de los miembros de la Suprema Corte estadunidense, a inicios de los años 70 (del siglo pasado), cuando el Presidente Nixon indicó 04 (cuatro) miembros para la referida Corte (Chief Justice Burger ${ }^{86}$

\footnotetext{
84 En esencia, los poderes estatales, siguiendo la idealización de Aristóteles, forman la denominada trias política, la cual hace mención Emmanuel Kant (KANT, Emmanuel. Doutrina do Direito. Traducción: Edson Bini. São Paulo: Ícone, 1993, página 152).

${ }^{85}$ Ralph A. Rossum y Alan Tarr circunscriben el término state action a la atuación del estado o de entidad privada asociada al estado ("under color of state"), siendo "the basis for redress under the Due Process and Equal Protection Clauses of the Fourteenth Amendments.” (ROSSUM, Ralph A. \& TARR, Alan. American Constitutional Law. Cases and interpretation. New York: St. Martin Press, $3^{\text {a }}$. Edición, página 744)

86 Asumió el cargo en la Corte Suprema en 1969.
} 
y los Justices Blackmun ${ }^{87}$, Powell ${ }^{88}$ y Rehnquist $\left.{ }^{89}\right)^{90}$. Esto porque, anteriormente, en la denominada “era Warren” (Chief Justice Earl Warren - 1953/1969) la Suprema Corte estadunidense, a través de innumerables decisiones inclusive, involucrando litigios entre particulares, exigió e impuso la creación de condiciones fácticas favorables al ejercicio/defensa del catálogo de derechos fundamentales declarados por el orden jurídico, asumiendo, de la misma manera, una función de concretizador de políticas públicas (rectius, politizando el proceso de juzgamiento constitucional), en un evidente ejemplo de jurisprudencia de los valores $^{91}$, o sea la idea de que la Ley Fundamental no es neutra, sino que está dotada de valores que deben ser obedecidos por toda la sociedad, inclusive la esfera privada.

A partir de la instalación de la "Court Burger" (1969), en vista de eso, la Suprema Corte estadunidense pasó a adoptar un concepto más estricto para el state action (restricción a la equiparación de la acción privada y pública). En el caso Jackson v. Metropolitan Edison Co. ${ }^{92}$, v.g., La Suprema Corte asentó que la interrupción de suministro de energía por falta de pago no estaba sujeta a la cláusula del due process of law (no reconoció la actividad de la empresa como longa manus del Estado de Pensilvania). En el caso Flag Bros Inc Brooks ${ }^{93}$, igualmente, fue decidido que el referido almacén no ejercía función delegada del Estado, lo que permitió al mismo vender bienes que estaban bajo su custodia, para costear las tasas impagas por los usuarios.

No obstante, al contrario de lo que apunta el "sentido común teórico", siguiendo las enseñanzas de Virgílio Afonso da Silva ${ }^{94}$, la doctrina del state action no buscó sedimentar el axioma de la no aplicabilidad de los derechos fundamentales en las relaciones privadas. Al

\footnotetext{
${ }^{87}$ Asumió el cargo en la Corte Suprema en 1970.

${ }^{88}$ Asumió el cargo en la Corte Suprema en 1972.

${ }^{89}$ Asumió el cargo en la Corte Suprema en 1972.

${ }^{90}$ Conforme Graig R. Ducat (DUCAT, Graig R. Constitutional Interpretation. Belmont: West Thomson Learning. $17^{\mathrm{a}}$ edición, 2000, páginas 1262-1263).

91 Conforme André Ramos Tavares. (TAVARES. André Ramos. Teoria da Justiça Constitucional. São Paulo: Saraiva. 2004, páginas 363-365). Son ejemplos emblemáticos de juzgados de la "Era Warren", en especial, involucrando la cohibición de la segregación/discriminación racial: Peterson v. City of Greenville, 373 U.S. 244, 83 S. Ct. 1119 (1963); Lombard v. Lousiana, 373 U.S. 267, 83 S. Ct. 1122 (1963); Robinson v. Florida, 378 U.S. 153, 84 S. Ct. 1693 (1964); Evans v. Newton, 382 U.S. 296, 86 S. Ct. 486 (1966); e Reitman v. Mulkey, 387, U.S. 369, 87, S. Ct. 1627 (1967).

92419 U.S. 345, 95 S. Ct. 449, 42 L.Ed.2d 477 (1974)

93 436, U.S. 149 (1978)

${ }^{94}$ SILVA, Virgílio Afonso da. A constitucionalização do direito. Os direitos fundamentais nas relações entre particulares. São Paulo: Malheiros, 2005, páginas 99-102.
} 
contrario, tal engendro jurisprudencial buscó romper esta limitación equiparando la acción privada a la acción pública, aunque de forma artificial. El referido autor apunta como ejemplos de la artificialidad en la jurisprudencia de la Suprema Corte estadunidense el caso Shelley $\boldsymbol{v}$ Kramer $^{95}$ en que fue reconocida la inconstitucionalidad, no con base en una violación a la Enmienda XIV (rectius, igualdad de derechos de los particulares, moradores de un condominio/lote, que celebraron contratos con cláusula prohibiendo la venta de inmuebles a "no blancos"), sino con fundamento en la decisión de la jurisdicción inferior "que prestó su fuerza y autoridad a la discriminación contraria de la Constitución”. La artificialidad de la argumentación de la Suprema Corte, por lo tanto, reside en el hecho de que si la cláusula contractual era constitucional, la decisión de mantener sus efectos, por la jurisdicción inferior, también debería serlo.

Concluye Virgílio Afonso da Silva que "Aunque que se insista que, en los Estados Unidos, los derechos fundamentales solamente vinculen las autoridades estatales, la práctica jurisprudencial ha mostrado otra realidad, aunque sea encubierta: la de que los derechos fundamentales vinculan, de alguna forma, a los individuos en sus relaciones entre sí." "96

\section{4-) Críticas a la eficacia externa o (alcance) horizontal de los derechos fundamentales.}

Al margen de las diversas concepciones acerca de la eficacia externa o (alcance) horizontal de los derechos fundamentales restan críticas en relación a su aplicabilidad.

La primera crítica deriva del standart de la autonomía privada (derecho de autodeterminación), inherente a las relaciones entre particulares y que difiere de la relación entre Estado y ciudadano. En el primer caso, impera, bajo la óptica jurídica, una relación de coordinación y autonomía entre las partes. En el segundo caso, figura en uno de los polos una institución dotada de poder de regulación unilateral y presa en un régimen de derecho público ${ }^{97}$.

\footnotetext{
95334 U.S. 1, 68 S. Ct. 836,92 L. Ed.1161 (1948). Los propietarios de lotes, que contenía la cláusula de restricción de venta del inmueble a "no blancos" promovieron la acción contra el adquiriente negro.

96 SILVA, Virgílio Afonso da. A constitucionalização do direito. Os direitos fundamentais nas relações entre particulares. São Paulo: Malheiros, 2005, página 102. El mencionado autor cita todavía como argumentos artificiales de la Suprema Corte lo siguiente juzgado: Burton v, Wilminton Parking Authority, 365 U.S. 715 (1961), donde la Suprema Corte estadunidense equiparó los actos practicados por un restaurante a actos estatales porque él se localizaba en una área pública.

97 Conforme Reinhold Zippelius. ZIPPELIUS, Reinhold. Introdução ao estudo do Direito. Belo Horizonte: Del Rey, 2006, página 130.
} 
La segunda crítica está radicada en la pérdida de la claridad conceptual de las normas de derecho privado, en la hipótesis de aplicación de las normas de derecho fundamental en las relaciones privadas.

Siguiendo esta orientación Konrad Hesse apunta que la superposición del Derecho Constitucional con el Derecho Privado "puede comportar una sensible restricción a la autonomía privada y, por eso, una considerable limitación de la libertad responsable, modificando de forma esencial, por lo tanto, la naturaleza y el significado del Derecho Privado" $" 98$.

Además, según Konrad Hesse, la baja densidad semántica de las normas de derechos fundamentales, en regla, amenaza la misión del Derecho Privado que debe tornar posible, con la aplicación de normas claras, detalladas y precisas (rectius, con alta densidad semántica) la modelación de las relaciones jurídicas privadas.

Sintetiza el mencionado jurista que "la ventaja de una amplia validad y efectividad de los derechos fundamentales paga el precio de una cierta inseguridad jurídica y de pérdida de la autonomía del Derecho Privado" 99.

\section{5-) La adopción por Brasil y por Argentina de una vulgata de la teoría de la eficacia inmediata o directa de vinculación (alcance) dos derechos fundamentales.}

Los Tribunales Superiores de Brasil y de Argentina, a pesar de haber juzgado casos involucrando la aplicación/vinculación de particulares a los derechos fundamentales, no estructuraron, de forma explícita, una tesis o modelo para a su resolución. Prevalece, por los casos juzgados en los Tribunales de los dos países, la idea de adopción de una vulgata de la teoría de la eficacia inmediata o directa de vinculación (alcance) de los derechos fundamentales.

En Brasil, el Supremo Tribunal Federal, al juzgar el recurso extraordinario RE $\mathrm{n}^{\mathrm{o}}$ 161243-6/DF ${ }^{100}$, admitió la eficacia directa de los derechos fundamentales en las relaciones laborales. El caso involucraba la recusa de aplicación del reglamento de una empresa aérea (Air

\footnotetext{
${ }^{98}$ HESSE, Konrad. "Significado dos Direitos Fundamentais”. Traducción para la lengua portuguesa: Carlos dos Santos Almeida. In Temas fundamentais de Direito Constitucional. São Paulo: Saraiva, 2009, página 61.

99 HESSE, Konrad. "Significado dos Direitos Fundamentais". Traducción para la lengua portuguesa: Carlos dos Santos Almeida. In Temas fundamentais de Direito Constitucional. São Paulo: Saraiva, 2009, página 62. 100 STF, RE 161243-6/DF, Segundo Grupo, Rel. Min. Carlos Veloso, DJ 19.12.1997. RTJ 172/604 (AgR).
} 
France) a los empleados brasileños, únicamente en razón de su nacionalidad (rectius, lesión al principio constitucional de la igualdad).

Consta en la referida decisión que "la discriminación que se basa en atributo, cualidad, nota intrínseca del individuo, como sexo, raza, nacionalidad, o credo religioso, etc., es inconstitucional". La fundamentación de la decisión, por lo tanto, no fue urdida con la preocupación (teórica) de evitar premisas generalizantes y monolíticas acerca el tema.

En el recurso extraordinario $\mathrm{RE} \mathrm{n}^{\mathrm{o}} 158.215 / \mathrm{RS}^{101}$, el Supremo Tribunal Federal analizó un caso involucrando desobediencia de normas estatutarias, de entidad de derecho privado (Cooperativa Mixta São Luiz), en relación a la expulsión de algunos de sus asociados/cooperados (no observancia del procedimiento de expulsión de sus asociados/cooperados, previsto en su estatuto constitutivo).

La decisión proferida por el Supremo Tribunal Federal fue en el sentido de que "la garantía de la amplia defensa está esculpida en precepto de orden público”, no pudiendo ser desobedecida en ningún ámbito (público o privado). Fue deferido a los cooperados/asociados expulsados un derecho público subjetivo a ser reintegrados a la entidad privada y ser juzgados en los términos del estatuto constitutivo de la cooperativa. Por lo tanto, un tema evidentemente de naturaleza privada (descumplimiento de cláusulas estatutarias de cooperativa), se transmutó en una decisión de la Corte Constitucional de Brasil, involucrando la eficacia de derechos fundamentales.

El Tribunal Superior de Trabajo (Brasil), en diversos casos juzgados ${ }^{102}$, reconoce igualmente, de forma implícita, la aplicabilidad de la teoría de la eficacia directa de los derechos fundamentales en las relaciones laborales.

En Argentina, la Cámara Nacional de Apelaciones Civiles consideró que una empresa había incurrido en discriminación arbitraria contra las mujeres ante la manifiesta desproporción verificada en la contratación de hombres para tareas que podrían ser realizadas por mujeres ${ }^{103}$.

${ }^{101}$ RTJ 164/757 (758).

102 Por ejemplo: TST, RR n ${ }^{\circ}$ 119037/2003-900-02-00.0, Tercer Grupo, Rel. Min. Carlos Alberto Reis de Paula, DJ 31.08.2007. Caso involucrando la discriminación (lesión al principio de isonomía) relativo a la falta de pago (injustificado) de gratificación por despido, concedido a apenas algunos empleados. TST, RR 2195/1999-00905-00.6, Primer Grupo, Rel. Min. João Oreste Dalazen, DJ 09.07.2004. Caso involucrando indemnización por daño moral, por lesión privacidad de empleada que era sometida a revista personal, y que tenía que desnudarse enfrente de representante del empleador. En este juzgado hay mención a la doctrina sobre la eficacia horizontal.

103 Caso "Fundación de Mujeres en Igualdad c. Freddo (LA LEY 2003-B, 970), apud BADENI, Gregorio. Manual de Derecho Constitucional. Buenos Aires: La Ley, 2011, página 320. 
En el caso "Ratto", la Sala V, de la Cámara Nacional de Apelaciones del Trabajo, por mayoría de votos, reconoció existir tratamiento discriminatorio por parte de la empresa al gratificar algunos operarios en detrimento de otros, cuando todos realizaban las mismas tareas ${ }^{104}$. Por afronta al art. 19, de la Constitución Argentina, la cuestión fue sometida a la Corte Suprema, que reconoció que el derecho del empleador de premiar a sus funcionarios se somete a su prudente juicio discrecional, bajo pena de desvirtuarse su ejercicio ${ }^{105}$. Posteriormente, la Corte Suprema, en el caso "Fernández c. Sanatorio Güemes" ponderó que el trabajador que demuestre que se encuentra en igualdad efectiva con otro, tiene derecho a igual tratamiento ${ }^{106}$.

En seguida, la Cámara Nacional de Apelaciones del Trabajo firmó posicionamiento en el sentido de que la reestructuración de una empresa no constituía un motivo objetivo que justificara la desigualdad en las retribuciones a sus empleados ${ }^{107}$.

Así como en Brasil, las decisiones de las Cortes Superiores de Argentina, mencionadas anteriormente, no están dotadas de aportes teóricos sobre la eficacia horizontal de los derechos fundamentales.

\section{6-) Conclusión.}

Las conclusiones apuntadas en este trabajo no se restringen a enunciar una lista de los temas abordados. Al contrario, busca una reflexión, a partir de lo que fue analizado.

La teoría de la eficacia inmediata tiene mayor razón de ser en los países que adoptan el control concentrado de constitucionalidad, pues tal tarea se concentra en las Cortes o Tribunales Constitucionales (v.g., Alemania, España, Italia). Esta concentración del control de constitucionalidad en un órgano (Consejo, Tribunal o Corte), promueve con mayor énfasis/eficacia, la concretización de un "sentido de Constitución”, aquí, incluidos los límites de la eficacia horizontal de los derechos fundamentales.

La "atomización" de la función de dador jurisdiccional (propio de los modelos difusos de control de constitucionalidad), en especial, sobre el tema involucrando la eficacia (alcance)

\footnotetext{
${ }^{104}$ CNTrab, Sala V, 14/12/64, “atto”, DT, 1966-449.

105 CSJN-Fallos, 265:242.

106 CSJN, 23/8/88, “Fernández c. Sanatorio Güemes”, DT 1989-580.

107 CNTrab, Sala VII, 20/3/89, “Miller c. ENTel”, DT, 1989-1350, apud KIPER, Claudio Marcelo. Derechos de las minorías ante la discriminación. Argentina:Hammurabi - José Luis Depalma/Editor, 1998, página 240.
} 
horizontal de los derechos fundamentales, genera en el área privada, inseguridad jurídica, conforme nos alerta Konrad Hesse, en la medida en que el derecho privado es suplantado por el Derecho Constitucional (fenómeno de la constitucionalización del derecho privado), quedando sometido a diversos entendimientos de jueces y órganos jurisdiccionales que normalmente, no adoptan un modelo o estructura para enfrentamiento del tema.

En Brasil y Argentina, la situación se agrava, ya que la constitucionalización del derecho suena como un "mantra jurídico", en la medida en que no se identifica con claridad el posicionamiento doctrinario y jurisprudencial mayoritario, acerca del papel que la constitución desempeña en el ordenamiento jurídico.

La teoría de los derechos fundamentales, diseminada en el mundo occidental, promovió la adopción, por el Poder Judicial, de un "derecho sustantivo racional", utilizado como instrumento de intervención prospectivo, orientado por principios, irguiendo su función creadora (en el sentido de promoción social y de control de la actividad política) ${ }^{108}$.

En un mundo globalizado, marcado por la "hipercomplejidad" social, no solamente el Estado amplió sus actividades y funciones, sino que también la sociedad participa cada vez más del ejercicio del poder, siendo innegable la necesidad de tutela estatal contra los abusos de los detentadores de poder social y económico, generadores de desigualdades o discriminaciones.

Por las mismas razones expuestas anteriormente, la responsabilidad del dador jurisdiccional queda potencializada, pues decisiones involucrando la aplicabilidad de los derechos fundamentales en las relaciones privadas pueden causar serios impactos (económicos, sociales) para una determinada categoría de personas. En Brasil, Maria Tereza Sadek ${ }^{109}$ coordinó $^{2}$ una encuesta indagando a los magistrados sobre las motivaciones de sus decisiones judiciales. La mayoría $(86,5 \%)$ verbalizó que se orientaba por parámetros legales. En el ámbito de la encuesta, se verificó también que a la mayoría (78,5\%) le importaban las consecuencias sociales de sus decisiones, y una parte $(36,5 \%)$ apuntaba para las consecuencias económicas. La conclusión del estudio apuntó que la falta de preocupación con los límites de decisión judicial, aún, daría oportunidad al cometimiento de excesos.

La sistemática procesal, tanto en Brasil como en Argentina, no está lista todavía para una resolución célere de los eventuales excesos que se puedan cometer por parte de órganos y miembros del Poder Judicial.

\footnotetext{
108 Conforme QUEIROZ, Cristina. Interpretação constitucional e poder judicial. Coimbra: Coimbra Editora, 2000, página 344 .

109 SADEK, Maria Tereza. Magistrados: uma imagem em movimento. Rio de Janeiro: Editora FGV, 2006.
} 
El problema, por lo tanto, reside en el modelo de control a ser adoptado. Según Virgílio Afonso da Silva ${ }^{110}$, la teoría de la aplicabilidad directa de los derechos fundamentales en las relaciones privadas es ampliamente minoritaria en prácticamente todos los países en que el tema es objeto de estudio sistemático. Para otros (v.g., Canotilho), la aplicación de los derechos fundamentales en las relaciones privadas, no es uniforme, reclamando soluciones diferenciadas.

El tema, en nuestro aspecto, tanto en Brasil como en Argentina, merece un análisis más detenido por parte de la doctrina y de la jurisprudencia, pues su análisis no debe limitarse al elenco de los posicionamientos doctrinarios y sus citaciones, con intuito de alcanzarse un efecto evocativo secundario, demostrando erudición. La discusión pasa necesariamente por la adopción y estructuración de un modelo (estructural y teorético) de aplicación de la eficacia horizontal de los derechos fundamentales.

Esta estructuración puede ser realizada bajo el enfoque de adopción de la eficacia mediata (de forma de no prescindir de la actuación legislativa estatal y conferir mayor seguridad en las relaciones privadas) o de la concentración de la competencia (jurisdiccional, política, etc.) a determinado órgano (Tribunal, Consejo o Corte) para ejercer el control de constitucionalidad, con exclusividad.

Resta, por fin, la paradoja de la idea del "pensamiento único" (Ignacio Ramonet) acerca del "sentido de constitución", más apto, bajo el enfoque economicista, atendiendo la realidad de un mundo globalizado contraponiéndose a la idea de garantía de la diferencia y de la pluralidad, propios de las Constituciones occidentales bajo su enfoque sustancial.

\section{7-) Bibliografía}

ALEXY, Robert. Teoria de los Derechos Fundamentales. Versión castellana: Ernesto Garzón Valdés. Madrid: Centro de Estudios Constitucionales, 1997.

BADENI, Gregorio. Manual de Derecho Constitucional. Buenos Aires: La Ley, 2011.

BIDART CAMPOS, German J. \& CARNOTA, Walter F. Derecho Constitucional Comparado. Buenos Aires: Ediar. Tomo II, 2000.

CRETELLA JÚNIOR, José. Droit Administratif Comparé. São Paulo: Editora da Universidade de São Paulo. 1973.

\footnotetext{
110 SILVA, Virgílio Afonso da. A constitucionalização do direito. Os direitos fundamentais nas relações entre particulares. São Paulo: Malheiros, 2005, página 94.
} 
DIAS, Jorge de Figueiredo (Org.). Internacionalização do Direito no novo século. Coimbra: Coimbra Editora, 2009.

DUCAT, Graig R. Constitutional Interpretation. Belmont: West Thomson Learning. $17^{\mathrm{a}}$ edição, 2000 .

DROMI, José Roberto. Sistema y valores administrativos. Buenos Aires: Ciudad Argentina, 2003.

FREITAS, Juarez de. O controle dos atos administrativos e os princípios fundamentais. $3^{\mathrm{a}}$. edição, São Paulo: Malheiros, 2004.

GORDILLO, Augustín \& FLAX, Gregorio (Orgs.). Derechos Humanos. Buenos Aires: Fundación de Derecho Administrativo. 6a edição, 2007.

HESSE, Konrad. "Significado dos Direitos Fundamentais". Tradução para língua portuguesa: Carlos dos Santos Almeida. In Temas fundamentais do Direito Constitucional. São Paulo: Saraiva, 2009.

KANT, Emmanuel. Doutrina do Direito. Tradução: Edson Bini. São Paulo: Ícone, 1993.

KIPER, Claudio Marcelo. Derechos de las minorias ante la discriminación. Argentina: Hammurabi - José Luis Depalma/Editor, 1998.

KOMMERS, Donald P. The Constitutional Jurisprudence of the Federal Republic of Germany. Durham and London: Duke University Press. 1997.

MANILI, Pablo Luis. El bloque de constitucionalidad. La recepción del Derecho Internacional de los Derechos Humanos en el Derecho Constitucional Argentino. Buenos Aires: La Ley. 2003. MARTINS, Ives Gandra. Uma breve teoria do poder. São Paulo: Revista dos Tribunais, 2009. NADAL, Fábio. A constituição como mito. O mito como discurso legitimador da Constituição. São Paulo: Método, 2006.

NADAL, Fábio \& RIBEIRO, Vauledir. Direito Administrativo. Série Exame de Ordem. São Paulo: Método. $7^{\text {a }}$ edição, 2010.

PIOVESAN, Flávia. Direitos humanos e o Direito Constitucional Internacional. São Paulo: Saraiva. 12a edição, 2011.

QUEIROZ, Cristina. Interpretação Constitucional e Poder Judicial. Coimbra: Coimbra Editora, 2000 . 
RADBRUCH, Gustav. Arbitrariedad legal y derecho supralegal. Tradução: María Isabel Azareto de Vásquez. Argentina: Abeledo-Perrot, 1962.

ROSSUM, Ralph A. \& TARR, Alan. American Constitutional Law. Cases and interpretation. New York: St. Martin Press. $3^{\text {a }}$. edição.

SADEK, Maria Tereza. Magistrados: uma imagem em movimento. Rio de Janeiro: Editora FGV, 2006.

SARLET, Ingo Wolfgang (Org.). O Direito Público em tempos de crise. Porto Alegre: Livraria do Advogado, 1999.

SARMENTO, Daniel (Org.). Interesses públicos versus interesses privados: Desconstruindo o princípio da supremacia do interesse público. Rio de Janeiro: Lumen Juris, 2005.

SCHWABE, Jürgen. Cinqüenta anos de Jurisprudência do Tribunal Constitucional Federal Alemão. Tradução para a língua portuguesa: Leonardo Martins (Org.), Beatriz Hennig, Mariana Bigelli de Carvalho, Tereza Maria de Castro e Vivianne Geraldes Ferreira. São Paulo: Konrad Adenauer Stiftung. 2005.

SILVA, Virgílio Afonso da. A Constitucionalização do direito. Os direitos fundamentais nas relações entre particulares. São Paulo: Malheiros, 2005.

TAVARES, André Ramos. Teoria da Justiça Constitucional. São Paulo: Saraiva. 2004.

TORRES, Ricardo Lobo (Org.). Teoria dos Diretos Fundamentais. Rio de Janeiro: Renovar, 1999.

VALE, Ionilton Pereira. "A eficácia horizontal dos direitos fundamentais: a aplicação dos direitos fundamentais no âmbito privado". In Revista de Direito Privado. São Paulo: Editora Revista dos Tribuanis, volume 44 (outubro-dezembro 2010).

ZIPPELIUS, Reinhold. Introdução ao estudo do Direito. Belo Horizonte: Del Rey, 2006. 